\title{
Photodynamic therapy in the management of potentially malignant and malignant oral disorders
}

\author{
Waseem Jerjes ${ }^{1,2,3,4,5,6^{*}}$, Zaid Hamdoon $n^{1,2,3,7,8}$ and Colin Hopper ${ }^{4,7,8}$
}

\begin{abstract}
Photodynamic therapy (PDT) is a minimally-invasive surgical tool successfully targeting premalignant and malignant disorders in the head and neck, gastrointestinal tract, lungs and skin with greatly reduced morbidity and disfigurement. The technique is simple, can commonly be carried out in outpatient clinics, and is highly acceptable to patients. The role of photodynamic therapy in the management of oral potentially malignant disorders and early oral cancer is being discussed.
\end{abstract}

\section{Introduction}

Potentially malignant oral disorders

Potentially malignant oral disorders, previously called potentially malignant lesions or conditions or oral dysplasia, are identified by exclusion of other white and red lesions. Leukoplakias and erythroplakias represent the majority of these disorders. Other, less commonly ones include oral lichen planus, oral submucous fibrosis, actinic cheilitis, xeroderma pigmentosum, Fanconi's anaemia and immunodeficiency (i.e. immunosuppressive agents, human immunodeficiency virus and chronic graft versus host disease) [1-3].

The worldwide prevalence of oral leukoplakia is about $2 \%$. Chronic smokers and drinkers are more likely to develop this disorder. There is conflicting evidence linking human papilloma virus to oral leukoplakia [1-3]. Clinical features can be homogeneous or non-homogeneous (erythroleukoplakia); the latter can be either speckled or nodular. Verrucous leukoplakia, another variant of nonhomogenous leukoplakia, has higher tendency to malignant transformation. The prevalence of oral erythroplakia, in selected studies, is less than $1 \%$. Risk factors are similar to the ones of oral leukoplakia [1-3].

\footnotetext{
* Correspondence: waseem_wk1@yahoo.co.uk

'Department of Surgery, Dijla University College, Baghdad, Iraq

2Department of Oral and Maxillofacial Surgery, Al-Yarmouk University College, Baghdad, Iraq

Full list of author information is available at the end of the article
}

The current gold standard for identifying dysplastic changes in tissue is histopathology, by identifying architectural changes and cellular atypia. Epithelial precursor lesions in this area involve squamous hyperplasia, mild, moderate, or severe dysplasia, and carcinoma in situ. Several authorities have identified substantial interobserver and intraobserver variation in the assessment of oral dysplastic lesions and their categorisation [1-3].

The management of these oral potentially malignant disorders is not well defined. However, centres around the world seem to agree on the basic principles. These include reducing risk/exposure factors, complete removal of the lesion and followed-up by continuous monitoring, which can be lifelong. The indications for active intervention are therapeutic, due to the presence of symptoms, and preventive, to pre-empt potential malignant transformation. Lesion removal is usually employed via surgical excision with cold instrumentation, laser surgery, cryosurgery and photodynamic therapy. The use of retinoids and mouthwash with attenuated adenovirus seems to have a role in the management [1-3].

\section{Oral cancer}

Cancers of the oral cavity are the sixth most common cancers in the world. Unfortunately the incidence continues to increase with moderate survival rates, despite the recent advances in surgery and radiotherapy [4-6].

Oral squamous cell carcinoma (OSCC) continues to affect more males than females with a ratio of $1.5-1$ in the fifth or sixth decade of their lives. However, there is 
an increasing trend of oral cancer affecting young people under the age of 45 years, accounting to about $6 \%$ of all age groups. Higher incidence of oral squamous cell carcinoma has been identified in South and Southeast Asia, Latin America, and the Caribbean, and in some parts of the western world, especially France. The incidence of oral cancer has also been found to be higher in ethnic minorities in other developed countries [4-6].

The most common oral sites to be affected with squamous cell carcinoma include the lateral border of the tongue, the ventral tongue and floor of mouth. In the Asian population, the buccal mucosa is commonly affected due to betel quit/tobacco chewing habits [4-6].

The tumour size is one of the most important factors affecting prognosis. This usually affects the clinician's ability to decide between ablative surgery, radiotherapy, chemotherapy, photodynamic therapy or just proceed to palliative care which could include a combination of any of the above therapies. Also, it is well documented that increased tumour size is related to local and regional disease spread, higher recurrence rates and poor prognosis [7-11].

Loco-regional spread to the cervical chain complicates treatment options and worsen the outcome. Several factors have been known to influence local and regional tumour spread to the lymphatics. These include the primary site, tumour volume, double DNA aneuploidy, poorly differentiated tumours, infiltrating-type invasive front and perineural and peri/endovascular invasion. Distant tumour spread occurs most commonly in uncontrolled local and regional disease and $\mathrm{N}$-stage disease [7-11].

The influence of the histological grading as a prognostic factor in oral squamous cell carcinoma have been documented in several studies and found to be a significant predictor of local and regional failure as well as tumour recurrence. Positive close tumour margins are usually associated with high risk of local recurrence and have a negative effect on survival [7-11].

\section{Photodynamic therapy}

Photodynamic therapy (PDT) is a minimally invasive modality, successfully targeting premalignant and malignant disorders in the head and neck, gastrointestinal tract, lungs and skin. Unlike other treatment options, it is associated with greatly reduced morbidity and disfigurement. The technique is simple and can usually be carried out in outpatient clinics, with a high patient-tolerance rate. PDT is based on initial sensitization of the target tissue with an agent with photosensitizing properties. The agent selectively accumulates in target tissue. The subsequent light delivery to the target tissue results in cellular destruction.

The photochemical reaction following PDT is nonthermal (cold). The photosensitising agents exhibit an inherently low systematic toxicity and, significantly, have a remarkably little effect on connective tissues, thus resulting in healing with minimal scarring. When used in hollow organs such as the airways, the luminal integrity is retained without fibrous tissue formation. Major blood vessels maintain their mechanical integrity as collagen and elastin are largely spared. This therapy can be applied in conjunction with any of the conventional treatment modalities (i.e. surgery, radiotherapy or chemotherapy). The treatment can be repeated as often as necessary since it has no cumulative toxicity [12-14].

At the time of writing, three first-generation photosensitisers have been approval by regulatory authorities. These are: Photofrin (porfimer sodium), 5-ALA (5-aminolaevulanic acid) and Verteporfin (BPD, benzoporphyrin derivative). Photofrin was the first photosensitiser to have received approval, and it is now licensed for the use in the oesophagus, lung, stomach, cervix and bladder. 5-ALA is a naturally occurring precursor in the heme biosynthetic pathway, and, to date, it has received approval only for non-malignant and pre-malignant disorders. It is converted to the endogenous photosensitiser protoporphyrin IX, which then can be activated by red, green and even blue light.

Development and introduction of newer photosensitisers and light delivery systems have substantially reduced treatment times and residual photosensitivity, while increasing the range of effective depth (i.e. necrosis and peri-lesional inflammation), [12-14]. A potent second-generation photosensitiser, Foscan (temoporfin; meta-tetrahydroxyphenyl chlorine) has been approved for treatment of advanced head and neck cancer. It is activated at $652 \mathrm{~nm}$, with a residual photosensitivity of 2-6 weeks [12-14].

Most photosensitisers are administered systemically, although some can be applied topically (i.e. for skin pathology applications). The depth of effect that can be achieved depends on the photosensitiser used. These are drugs that are incorporated directly into cellular membranes, but they do not seem to accumulate within cell nuclei. The direct cytotoxic activity and microvascular damage contribute to the destruction of tumour cells, which is manifested as inflammatory swelling and formation of necrotic tissue. This tissue eventually sloughs away (or is resorbed), followed by normal healing and reepitheliasation [12-14]. Systemic administration of the photosensitiser leads to a period of unwanted residual photosensitivity that must be managed until the drug is eliminated [12-14].

Treatment times vary substantially. The time is related to the absorption of light by the photosensitiser and also the efficiency of transfer of light energy to oxygen. Lightemitting diodes and xenon lamp sources are commonly used for dermatological application, but lasers are the most convenient and controllable light source [12-14]. 


\section{Clinical studies}

The management of patients with premaligant lesions of the oral mucosa in "field cancerization", with multicentric foci of invasion, presents a considerable problem for the surgeon. Radiotherapy is not always feasible since it can only be given once and is associated with significant local morbidity. Grant et al. [15] reported the use of PDT to treat 11 patients with "field cancerization" occurring in the oral cavity. Six patients had multiple primary cancers and five had single primary tumours. Six to eight weeks later, treated areas in 10 of the 11 patients showed a complete response to PDT. One patient had areas of residual leukoplakia; while 2 patients developed further areas of leukoplakia or erythroplakia within 12 months. However, no patient has had evidence of recurrent invasive carcinoma in the treated areas.

In another study [16], 18 patients were treated with ALAPDT for histologically proven premalignant and malignant lesions of the mouth. There was a consistent epithelial necrosis with excellent healing in all cases. This study found that ALA-PDT is a simple and effective way to manage these patients. More recently, Tsai et al. [17] developed a light-emitting diode (LED) array combined with topical 5aminolevulinic acid (ALA) for photodynamic therapy (PDT) and evaluated its effectiveness for the treatment of potentially malignant oral disorders. The clinical part of the study included a total of 33 oral lesions which included leukoplakia, verrucous hyperplasia, erythroleukoplakia, and verrucous carcinoma. Using the LED light source, a total of 24 leukoplakia lesions were treated with ALA-PDT. The result was, a complete response in three, a partial response in nine, and no response in twelve lesions. In the five lesions of verrucous hyperplasia, complete responses were found in four while partial response, in the remaining one patient. Partial responses were found in the two erythroleukoplakia and one verrucous carcinoma lesions. They concluded that ALA-PDT is effective for premalignant disorders. We agree with the statement but believe that higher response rates can be achieved.

An interesting study by Rigual et al. [18], assessing the response of dysplasia, carcinoma in situ, and T1 carcinoma of the oral cavity and larynx to photodynamic therapy with porfimer sodium. Responses were evaluated at 1 week and at 1 month and then at 3-month intervals thereafter. Twenty-four patients had a complete response, 1 had a partial response, and 1 had no response. Three patients with oral dysplasia with an initial complete response experienced recurrence in the treatment field. All the patients with no response, a partial response, or recurrence after an initial complete response underwent salvage treatment. Temporary morbidities included oedema, pain, hoarseness, and skin phototoxicity. They concluded that porfimer sodium-PDT is an effective treatment option, with no permanent sequelae.
Biel [19] reported his series of 276 patients with early carcinomas of the oral cavity and larynx. His cure rates with a single treatment for early laryngeal and oral cancers were $91 \%$ and $94 \%$, respectively. He postulated that PDT is an effective primary and alternative treatment modality for early oral cavity and laryngeal cancers. An earlier study by Hopper et al. [20] on 121 early oral squamous cell carcinoma patients treated by mTHPC-PDT showed a complete response in $85 \%$ of protocol-compliant patients (97 of 114 patients). A complete response was maintained in $85 \%$ of responders at 1 year and in $77 \%$ at 2 years. One- and 2 year actuarial survival rates were $89 \%$ and $75 \%$, respectively. In the opinion of the investigators, tumour clearance was accompanied by excellent cosmetic and functional results, without impact on the patients' performance status.

\section{Recent studies in our unit}

In a prospective study [21] carried out at the UCLH Head and Neck Centre, a total of 147 consecutive patients with potentially malignant oral disorders were treated with surface illumination PDT, using 5-ALA or $\mathrm{mTHPC}$ as the photosensitiser (Figure 1). The average age was $53 \pm 8.9$ years. The patients' recovery was uneventful and no complications were noted. Study parameters consisted of clinical and histopathological features, rate of recurrence and malignant transformation. The patients were followed-up for a mean of 7.3 years.

Ex- and current lifelong smokers formed $84.4 \%$ of the recruited patients, while people who currently smoked and drank, formed $38.1 \%$ (56 patients) of the cohort. Homogenous leukoplakias were identified in 55 patients, non-homogenous leukoplakias in 73 patients, whereas 19 patients had erythroplakias. Erythroplakias were mainly identified in heavy lifelong smokers. The most frequent sites for the lesion were lateral border of tongue, floor of mouth and retromolar area. Moderate dysplasia was identified in 33 patients while 63 patients had severe dysplasias; 32 patients had a histopathological diagnosis of carcinoma in situ.

The rate of recurrence following PDT was approximately $11.6 \%$. Malignant transformation was observed in 11 patients $(7.5 \%)$, in the tongue, floor of mouth and retromolar area. Recurrence and malignant transformation was mainly identified in erythroplakias and nonhomogenous leukoplakias. The final outcome of the cohort showed that $11(7.5 \%)$ suffered from progressive disease, 5 (3.4\%) had stable disease, 12 (8.2\%) were considered partially responsive to the therapy. Complete response was identified in $119 / 147$ patients (81\%). These results provided conclusive evidence that 5-ALA-PDT and $\mathrm{mTHPC}$-PDT offer an effective alternative treatment for potentially malignant oral disorders. 


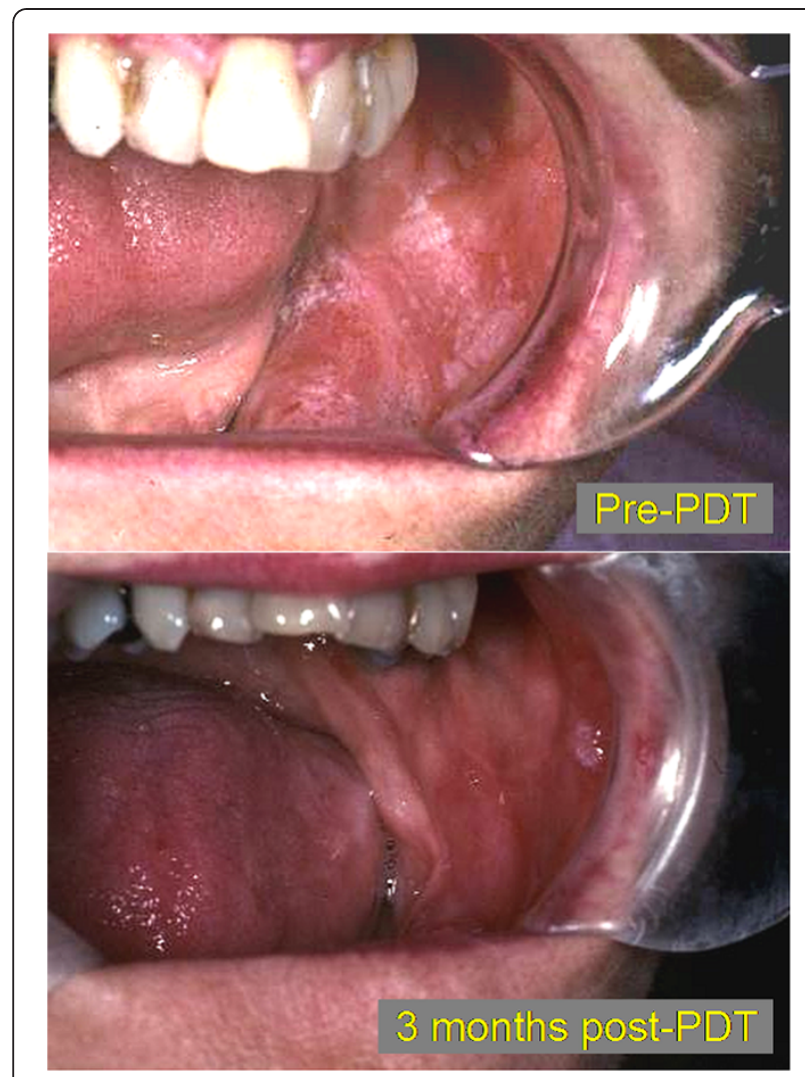

Figure 1 Clinical images showing response of moderate oral dysplasia to photodynamic therapy. Adapted with permission from: Jerjes W, Upile T, Hamdoon Z, Mosse CA, Akram S, Hopper. Photodynamic therapy outcome for oral dysplasia. Lasers Surg Med. 2011 Mar:43(3):192-9.

In another prospective study [22] carried out at the same centre, a cohort of 38 patients suffering from T1/T2 N0 oral cancer were subjected to mTHPC-photodynamic therapy and followed up for a minimum of 5 years (Figure 2). Clinicopathological parameters, recurrence, survival and disease progression were assessed.

The mean age at the $1^{\text {st }}$ diagnosis of OSCC was 58.0 years. Common clinical presentation was an ulcer in the tongue, floor of mouth or buccal mucosa. Current/ ex-smokers represented $89.5 \%$ of the cohort; while current/ex-drinkers were $86.8 \%$. Clinically 29 patients had T1 disease while 9 had T2 disease. Histopathological diagnosis showed 12 patients with well differentiated SCC, 16 moderately-differentiated and 10 with poorlydifferentiated cancer. All patients underwent mTHPCPDT and were followed-up postoperatively.

A 5-year post-PDT review, 26/38 patients showed completely normal clinical appearance at the primary tumour site. Nine patients showed complete response after one round of PDT treatment, 22 patients underwent two rounds and 7 patients had three rounds. Recent biopsies from the study cohort showed that 15 had normal mucosa, 5 had hyperkeratinisation, 10 had dysplastic changes, 2 had carcinoma in situ and 6 showed recurrent SCC. Overall recurrence was $15.8 \%$ and the 5year survival was $84.2 \%$. Death from loco-regional and distant disease spread occurred in 3 patients. The recurrence group comprised 6 patients. The mean age of $1^{\text {st }}$ diagnosis of the recurrence group was 59.3 years.

Most common presentation was an ulcer involving the buccal mucosa or retromolar area, identified in current/ ex-smokers and current/ex-drinkers. The surgical margins in this group were also evaluated following laser or surgical excision, neck dissection and reconstruction. Based on our experience, we conclude that mTHPCphotodynamic therapy offers a modality comparable to other traditional interventions in the management of low-risk tumours of the oral cavity, with a considerably less morbidity.

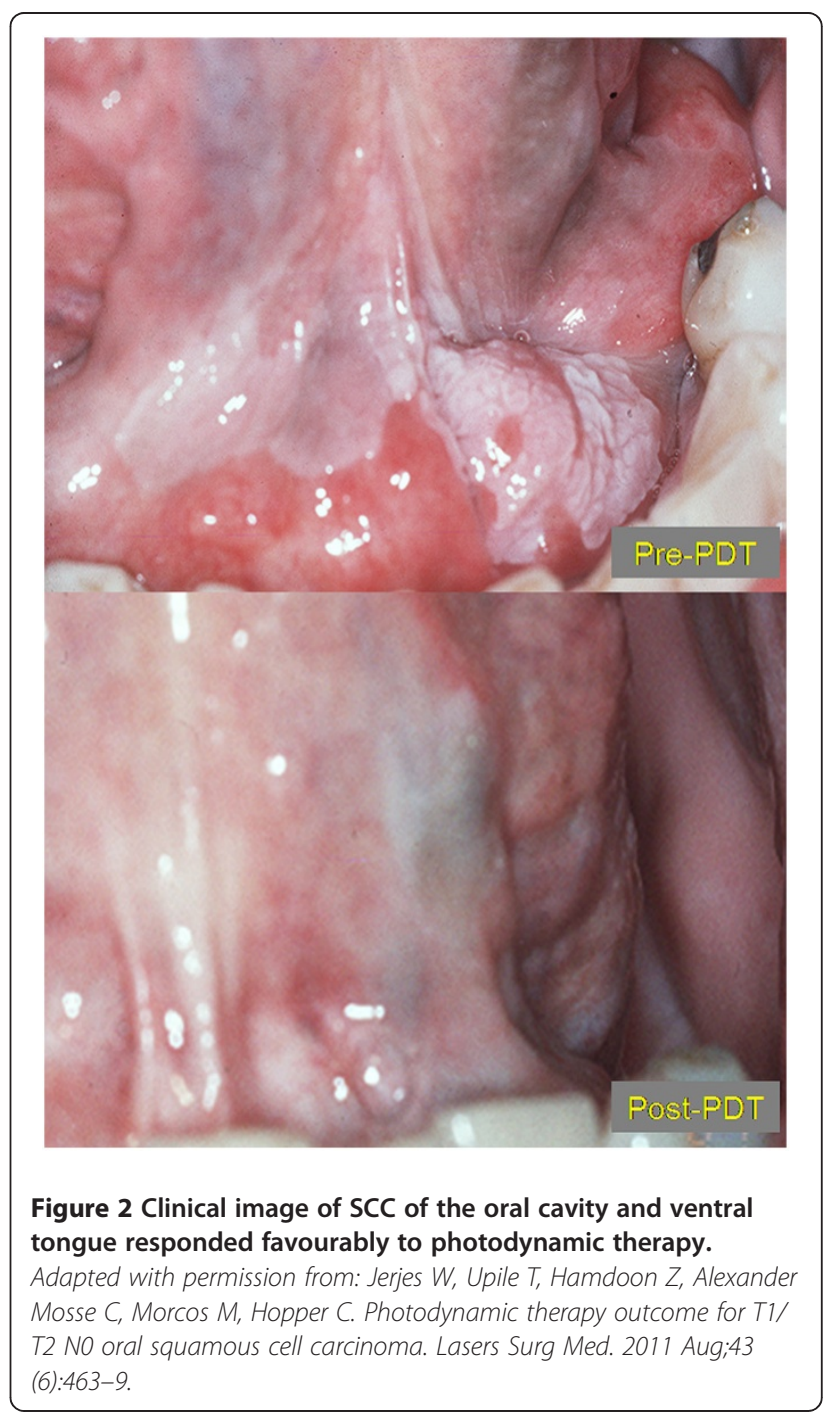




\section{Discussion}

Photodynamic therapy can be delivered under local or general anaesthesia and the delivery method can include surface illumination or interstitial application. The selective uptake and retention of a local or systemically administered photosensitiser in pathological tissue is an important factor in PDT. When tumour:normal tissue photo-differentiation has reached an optimum, the photosensitiser is activated by non-thermal light of the appropriate wavelength. This results either in the production of oxygen free radicals (type I mechanism) or the formation of intracellular singlet oxygen (type II mechanism), which causes tumour cell death by intracellular oxygenation and vascular shutdown mechanisms [12-14] Although both mechanisms can be activated at the same time.

The notable adverse events in the immediate post treatment phase include pain and swelling. Pain was experienced at some stage following PDT by all of the patients. In most cases, pain commenced 24-48 hours following completion of treatment and lasted for several days [23]. In some instances oral opiate analgesia was necessary. The use of a local analgesic and anti-inflammatory spray prior to meals was found to be useful.

Pain was present in $82 \%$ of PDT-treated patients while swelling was limited to only $10 \%$. Pain was generally mild to moderate in severity and commonly persisted for 24 weeks, decreasing in intensity as the healing progressed. The pain usually required short-term treatment with non-steroidal anti-inflammatory drugs (NSAIDs), in addition to opiates. The reporting of pain was mirrored by a temporary rise in white blood cell levels, which followed the induction of tissue necrosis and the onset of acute and chronic inflammatory responses [20].

The major side effect of PDT is residual systemic photosensitization, which lasts for several days or weeks depending on the type of photosensitiser used. This is caused by minor concentrations of the photosensitiser in the skin and may lead to oedema, sunburn, or even superficial skin necrosis when the skin is exposed to bright light.

\section{Limitations}

So far 5-aminolevulinic acid (5-ALA) is the only photosensitiser that can be applied topically; all others have to be given intravenously. The advantage of topically applied ALA is the complete lack of systemic photosensitivity and therefore, ALA-treated patients do not have to avoid exposure to light following treatment. The major disadvantage of a topically applied photosensitiser is the shallow treatment depth of only $1-2 \mathrm{~mm}$ that can be obtained. Therefore only very superficial lesions of less than $1 \mathrm{~mm}$ can be treated successfully with topical application $[12-14,23]$.
There is little current published data assessing the use of PDT in the treatment of early tumours (TNM stage T1/T2 N0) of the head \& neck. The advantages of the use of PDT compared to radiotherapy include its potential for multiple administration, the ability to treat a higher resolution tumour volume when combined with ultrasound guidance for interstitial administration. Its particularly useful for application in cases of 'field effect' of mucosal cancerisation, without jeopardising the potential to use other therapeutic modalities (further surgery, interstitial PDT or radiotherapy) [12-14,23].

The disadvantages to the technology is that it involves some specialised equipment and training. There is a large capital outlay however, this is easily negated by the potential benefits to the patient (quicker administration, better cosmesis and quality of life) when compared to some more conventional treatment schedules [12-14,23].

Difficulties arise when the tumour starts to metastasise through the lymphatic chain. In such cases it is not feasible to induce a therapeutic photochemical reaction in a whole area of the body (i.e. neck, groin, axilla). A photochemical reaction can be induced in single or multiple lymph nodes under image-guidance but this can be sometimes difficult to perform when dealing with a complex lymphatic map as in the neck. Alternative therapies (i.e. ablative surgery, radiotherapy, chemotherapy) at this stage can lead to severe problems which can affect form and function [12-14,20,23].

So far, photodynamic therapy (also known as the fourth modality, the first three being surgery, radiotherapy and chemotherapy) has been successfully used in the management of a variety of pathologies from different anatomical sites. These include the head and neck, brain, lungs, hepatobiliary tree and other gastrointestinal and urological pathologies, skin, gynaecological conditions and in vascular anomalies [24-39].

\section{Conclusions}

Photodynamic therapy is an appropriate stand alone intervention, or as an adjunct to surgery. It is minimally invasive and can be applied repeatedly at the same site with no cumulative toxicity. It is also a viable option where radiotherapy is contraindicated. This modality causes tissue destruction via the interaction between oxygen (in tumour tissue), light (of a specific wavelength) and a photosensitizing drug. The photosensitiser is administered intravenously or topically. It is selectively retained in the target tissues. The nature of the tissue dictates the interval for maximum accumulation. Laser light can then be directed at the tumour following a sufficient drug-light interval, thus activating the drug and initiating the cold (non-thermal) photochemical reaction.

In summary, premalignant and malignant changes in the mouth, often widespread, are frequently excised or 
lasered. Photodynamic therapy (PDT) offers yet another option, on its own or in combination with other modalities. Interaction of light with previously administered photosensitizing agent leads to a local tissue necrosis of target tissue. There is no cumulative toxicity and the healing is with remarkably little scarring.

\section{Competing interests}

The authors declare no competing interests.

\section{Authors' contributions}

All authors have contributed intellectually and to the writing of this manuscript. All authors read and approved the final manuscript.

\section{Acknowledgement}

We acknowledge the help of Tahwinder Upile during the writing up of this article.

\section{Author details}

'Department of Surgery, Dijla University College, Baghdad, Iraq. ${ }^{2}$ Department of Oral and Maxillofacial Surgery, Al-Yarmouk University College, Baghdad, Iraq. ${ }^{3}$ Department of Oral Surgery, Al-Mustansiriya University, Baghdad, Iraq. ${ }^{4}$ Department of Surgery, University College London Medical School, London, UK. ${ }^{5}$ Leeds Institute of Molecular Medicine, Leeds, United Kingdom. ${ }^{6}$ Department of Surgery, Leeds Teaching Hospitals NHS Trust, Leeds, United Kingdom. ${ }^{7}$ Oral and Maxillofacial Unit, UCL Eastman Dental Institute, London, United Kingdom. ${ }^{8} \mathrm{UCLH}$ Head and Neck Centre, London, United Kingdom.

\section{Received: 10 April 2012 Accepted: 12 April 2012}

Published: 30 April 2012

\section{References}

1. Van der Waal I: Potentially malignant disorders of the oral and oropharyngeal mucosa; terminology, classification and present concepts of management. Oral Oncol 2009, 45(4-5):317-23.

2. Mehanna HM, Rattay T, Smith J, McConkey CC: Treatment and follow-up of oral dysplasia - a systematic review and meta-analysis. Head Neck. 2009, 31(12):1600-9

3. van der Waal I: Potentially malignant disorders of the oral and oropharyngeal mucosa; present concepts of management. Oral Oncol 2010, 46(6):423-5.

4. Bagan JV, Scully C: Recent advances in Oral Oncology 2007: epidemiology, aetiopathogenesis, diagnosis and prognostication. Oral Oncol 2008, 44(2):103-8.

5. Warnakulasuriya S: Global epidemiology of oral and oropharyngeal cancer. Oral Oncol 2009, 45(4-5):309-16.

6. Jerjes W, Upile T, Petrie A, Riskalla A, Hamdoon Z, Vourvachis M, Karavidas K, Jay A, Sandison A, Thomas GJ, Kalavrezos N, Hopper C: Clinicopathological parameters, recurrence, locoregional and distant metastasis in 115 T1-T2 oral squamous cell carcinoma patients. Head Neck Oncol 2010, 2:9.

7. Noguchi M, Kinjyo H, Kohama Gl, Nakamori K: Invasive front in oral squamous cell carcinoma: image and flow cytometric analysis with clinicopathologic correlation. Oral Surg Oral Med Oral Pathol Oral Radiol Endod 2002, 93(6):682-7.

8. Garzino-Demo P, Dell'Acqua A, Dalmasso P, Fasolis M, La Terra Maggiore GM, Ramieri G, Berrone S, Rampino M, Schena M: Clinicopathological parameters and outcome of 245 patients operated for oral squamous cell carcinoma. J Craniomaxillofac Surg 2006, 34(6):344-50.

9. Shah JP, Gil Z: Current concepts in management of oral cancer-surgery Oral Oncol 2009, 45(4-5):394-401.

10. Mazeron R, Tao Y, Lusinchi A, Bourhis J: Current concepts of management in radiotherapy for head and neck squamous-cell cancer. Oral Oncol 2009, 45(4-5):402-8

11. Specenier PM, Vermorken JB: Current concepts for the management of head and neck cancer: chemotherapy. Oral Oncol 2009, 45(4-5):409-15.

12. Hopper C: Photodynamic therapy: a clinical reality in the treatment of cancer. Lancet Oncol 2000, 1:212-9.
13. Jerjes W, Upile T, Betz CS, El Maaytah M, Abbas S, Wright A, Hopper C: The application of photodynamic therapy in the head and neck. Dent Update 2007, 34(8):478-80.

14. Jerjes W, Upile T, Hamdoon Z, Nhembe F, Bhandari R, Mackay S, Shah P, Mosse CA, Brookes JA, Morley S, Hopper C: Ultrasound-guided photodynamic therapy for deep seated pathologies: prospective study. Lasers Surg Med 2009, 41(9):612-21.

15. Grant WE, Hopper C, Speight PM, Macrobert AJ, Bown SG: Photodynamic therapy of malignant and premalignant lesions in patients with 'field cancerization' of the oral cavity. J Laryngol Otol 1993, 107(12):1140-5.

16. Fan KF, Hopper C, Speight PM, Buonaccorsi G, MacRobert AJ, Bown SG: Photodynamic therapy using 5-aminolevulinic acid for premalignant and malignant lesions of the oral cavity. Cancer 1996, 78(7):1374-83.

17. Tsai JC, Chiang CP, Chen HM, Huang SB, Wang CW, Lee Ml, Hsu YC, Chen CT, Tsai T: Photodynamic Therapy of oral dysplasia with topical 5-aminolevulinic acid and light-emitting diode array. Lasers Surg Med 2004, 34(1):18-24.

18. Rigual NR, Thankappan K, Cooper M, Sullivan MA, Dougherty T, Popat SR, Loree TR, Biel MA, Henderson B: Photodynamic therapy for head and neck dysplasia and cancer. Arch Otolaryngol Head Neck Surg 2009, 135(8):784-8.

19. Biel MA: Photodynamic therapy treatment of early oral and laryngeal cancers. Photochem Photobiol 2007, 83(5):1063-8.

20. Hopper C, Kübler A, Lewis H, Tan IB, Putnam G: mTHPC-mediated photodynamic therapy for early oral squamous cell carcinoma. Int $J$ Cancer 2004, 111(1):138-46.

21. Jerjes W, Upile T, Hamdoon Z, Mosse CA, Akram S, Hopper: Photodynamic therapy outcome for oral dysplasia. Lasers Surg Med 2011, 43(3):192-9.

22. Jerjes W, Upile T, Hamdoon Z, Alexander Mosse C, Morcos M, Hopper C: Photodynamic therapy outcome for T1/T2 N0 oral squamous cell carcinoma. Lasers Surg Med 2011, 43(6):463-9.

23. Grant WE, Speight PM, Hopper C, Bown SG: Photodynamic therapy: an effective, but non-selective treatment for superficial cancers of the oral cavity. Int J Cancer 1997, 71(6):937-42.

24. Usuda J, Kato H, Okunaka T, Furukawa K, Tsutsui H, Yamada K, Suga Y, Honda H, Nagatsuka Y, Ohira T, Tsuboi M, Hirano T: Photodynamic therapy (PDT) for lung cancers. J Thorac Oncol 2006, 1(5):489-93.

25. Corti L, Toniolo L, Boso C, Colaut F, Fiore D, Muzzio PC, Koukourakis MI, Mazzarotto R, Pignataro M, Loreggian L, Sotti G: Long-term survival of patients treated with photodynamic therapy for carcinoma in situ and early non-small-cell lung carcinoma. Lasers Surg Med 2007, 39(5):394-402.

26. Minnich DJ, Bryant AS, Dooley A, Cerfolio RJ: Photodynamic laser therapy for lesions in the airway. Ann Thorac Surg 2010, 89(6):1744-8. discussion 1748-9.

27. Overholt BF, Wang KK, Burdick JS, Lightdale CJ, Kimmey M, Nava HR, Sivak MV Jr, Nishioka N, Barr H, Marcon N, Pedrosa M, Bronner MP, Grace M, Depot M: International Photodynamic Group for High-Grade Dysplasia in Barrett's Esophagus. Five-year efficacy and safety of photodynamic therapy with Photofrin in Barrett's high-grade dysplasia. Gastrointest Endosc 2007, 66(3):460-8.

28. Keeley SB, Pennathur A, Gooding W, Landreneau RJ, Christie NA, Luketich J: Photodynamic therapy with curative intent for Barrett's esophagus with high grade dysplasia and superficial esophageal cancer. Ann Surg Oncol 2007, 14(8):2406-10.

29. Tanaka T, Matono S, Nagano T, Murata K, Sueyoshi S, Yamana H, Shirouzu K, Fujita $\mathrm{H}$ : Photodynamic therapy for large superficial squamous cell carcinoma of the esophagus. Gastrointest Endosc 2011, 73(1):1-6

30. Wang JB, Liu LX: Use of photodynamic therapy in malignant lesions of stomach, bile duct, pancreas, colon and rectum. Hepatogastroenterology 2007, 54(75):718-24.

31. Fan BG, Andrén-Sandberg A: Photodynamic therapy for pancreatic cancer. Pancreas 2007, 34(4):385-9.

32. Pinthus JH, Bogaards A, Weersink R, Wilson BC, Trachtenberg J: Photodynamic therapy for urological malignancies: past to current approaches. J Urol 2006, 175(4):1201-7.

33. Skyrme RJ, French AJ, Datta SN, Allman R, Mason MD, Matthews PN: A phase- 1 study of sequential mitomycin $C$ and 5 -aminolaevulinic acid-mediated photodynamic therapy in recurrent superficial bladder carcinoma. BJU Int 2005, 95(9):1206-10.

34. Betz CS, Rauschning W, Stranadko EP, Riabov MV, Albrecht V, Nifantiev NE, Hopper C: Optimization of treatment parameters for Foscan(R)-PDT of basal cell carcinomas. Lasers Surg Med 2008, 40(5):300-11. 
35. Calzavara-Pinton PG, Venturini M, Sala R, Capezzera R, Parrinello G, Specchia C, Zane C: Methylaminolaevulinate-based photodynamic therapy of Bowen's disease and squamous cell carcinoma. Br J Dermatol 2008, 159 (1):137-44.

36. Brown SB, Brown EA, Walker I: The present and future role of photodynamic therapy in cancer treatment. Lancet Oncol 2004, 5(8):497-508.

37. Triesscheijn M, Baas P, Schellens JH, Stewart FA: Photodynamic therapy in oncology. Oncologist 2006, 11(9):1034-44.

38. Fayter D, Corbett M, Heirs M, Fox D, Eastwood A: A systematic review of photodynamic therapy in the treatment of pre-cancerous skin conditions, Barrett's oesophagus and cancers of the biliary tract, brain, head and neck, lung, oesophagus and skin. Health Technol Assess 2010, 14 (37):1-288.

39. Jerjes W, Upile T, Hamdoon Z, Mosse CA, Akram S, Morley S, Hopper C: Interstitial PDT for vascular anomalies. Lasers Surg Med 2011, 43(5):357-65.

doi:10.1186/1758-3284-4-16

Cite this article as: Jerjes et al.: Photodynamic therapy in the management of potentially malignant and malignant oral disorders.

Head \& Neck Oncology 2012 4:16.

\section{Submit your next manuscript to BioMed Central and take full advantage of:}

- Convenient online submission

- Thorough peer review

- No space constraints or color figure charges

- Immediate publication on acceptance

- Inclusion in PubMed, CAS, Scopus and Google Scholar

- Research which is freely available for redistribution 